Antarctic Science 32(4), 239-247 (2020) (c) The Author(s), 2020. Published by

Cambridge University Press 2020. This is an Open Access article, distributed under the terms of the Creative Commons Attribution licence (http://creativecommons.org/licenses/ by/4.0/), which permits unrestricted re-use, distribution, and reproduction in any medium, provided the original work is properly cited.

doi:10.1017/S0954102020000140

\title{
Reproductive traits and age of barbeled plunderfishes from the Weddell Sea
}

\author{
MARIO LA MESA (1), FORTUNATA DONATO², EMILIO RIGINELLA ${ }^{3}$, CHIARA PAPETTI4,5, \\ ELYSE PARKER ${ }^{6}$ and THOMAS J. NEAR ${ }^{\mathbf{6}}$ \\ ${ }^{1}$ CNR, Institute of Polar Sciences (ISP), clo Area di Ricerca di Bologna, via P. Gobetti 101, 40129 Bologna, Italy \\ ${ }^{2}$ CNR, Institute of Biological Resources \& Marine Biotechnology (IRBIM), Largo Fiera della Pesca, 60125, Ancona, Italy \\ ${ }^{3}$ Zoological Station Anton Dohrn, Villa Comunale, 80121 Naples, Italy \\ ${ }^{4}$ Department of Biology, Padua University, Via G Colombo 3, 35121 Padua, Italy \\ ${ }^{5}$ Consorzio Nazionale Interuniversitario per le Scienze del Mare (CoNISMa), 00196 Roma, Italy \\ ${ }^{6}$ Department of Ecology \& Evolutionary Biology \& Peabody Museum of Natural History, Yale University, PO Box 208106, \\ New Haven, CT 06520, USA \\ mario.lamesa@cnr.it
}

\begin{abstract}
The genus Pogonophryne is the most species-rich genus of barbeled plunderfishes (Artedidraconidae) and includes more than 25 poorly known species endemic to the Southern Ocean. In this study, we provide new data on the age and reproductive traits of some species of Pogonophryne from the southern Weddell Sea, inferred through otolith reading and histological analyses of gonads. Individual age estimates ranged between 16 and 18 years for Pogonophryne barsukovi and Pogonophryne immaculata and between 10 and 22 years for Pogonophryne scotti. As is commonly found in notothenioids, P. barsukovi followed a group-synchronous type of ovarian development, with pre-vitellogenic and vitellogenic oocytes forming two well-separated egg-size groups. A single spawning female in the sample produced $\sim 1097$ eggs and 7.9 eggs $\mathrm{g}^{-1}$. The sample of P. immaculata consisted exclusively of developing males, with testes composed of cysts of spermatogonia, spermatocytes and spermatids. Pogonophryne scotti was the most abundant species, including relatively small males at immature or developing stages of gonad development. Larger females were regressing, being characterized by ovaries with postovulatory follicles and atretic oocytes. Based on the macroscopic and histological analyses of gonads, the spawning season would take place in autumn for $P$. barsukovi and $P$. immaculata and in spring-early summer for $P$. scotti.
\end{abstract}

Received 4 November 2019, accepted 28 January 2020

Key words: Artedidraconidae, life history, Southern Ocean

\section{Introduction}

The Artedidraconidae includes small- to medium-sized benthic species endemic to the Southern Ocean commonly known as plunderfishes. The genus Pogonophryne is the most species-rich group within the family, consisting of more than 25 recognized species, most of which have been described in the last decade (e.g. Eakin et al. 2008, 2009, Balushkin et al. 2010, Balushkin \& Korolkova 2013, Balushkin \& Spodareva 2013, Shandikov \& Eakin, 2013, Shandikov et al. 2013, Spodareva \& Balushkin 2014). The taxonomic composition of the genus was first described on the basis of body coloration, number of vertebrae and second dorsal fin rays, distinguishing three main groups of fish: the unspotted group (Pogonophryne albipinna), the dorsally unspotted group (Pogonophryne scotti) and the dorsally spotted group (Eakin 1977, 1990).
More recently, the last group was further subdivided in three different groups (Pogonophryne marmorata, Pogonophryne barsukovi, Pogonophryne mentella), each including one or more species (Balushkin \& Eakin 1998).

Compared to other genera of plunderfishes, Pogonophryne is characterized by a wide and depressed head, poorly to well-developed post-temporal ridges, a wide interorbital space and a snout as long as the orbit diameter (Eakin 1990). Most species are only known from the holotype or type series, with occurrence limited to single spots or restricted areas around the Antarctic continent. A few other more abundant species have generally a circum-Antarctic distribution, including areas as far north as the South Orkney Islands (Eakin 1990). The species of Pogonophryne are distributed over a wide depth range, being found on the continental shelf and slope from inshore waters down to more than $2500 \mathrm{~m}$ depth (Eastman 2017). 
Table I. Sampling data of barbeled plunderfishes (genus Pogonophryne) during the Polarstern cruises (PS82 and PS96) conducted in the Weddell Sea in the 2013-14 and 2015-16 summer seasons.

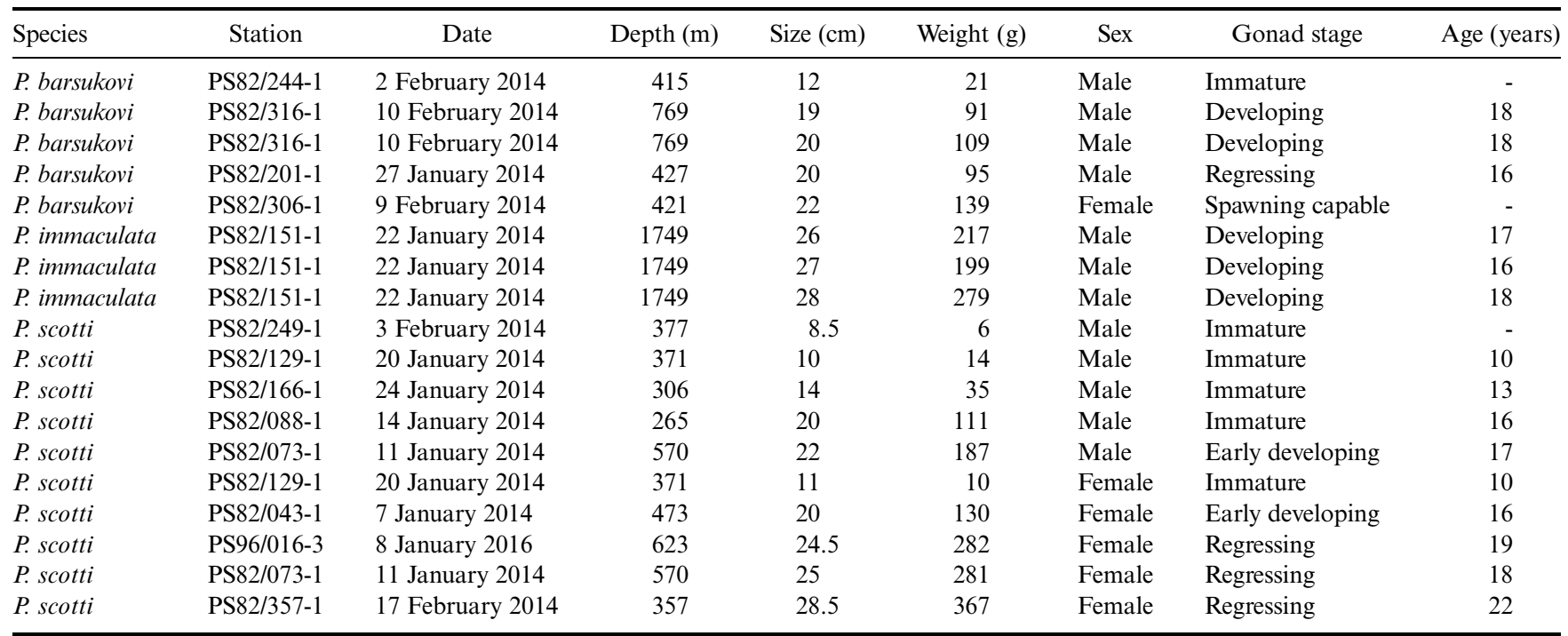

Because of their low abundance and generally deep distribution, the biological characteristics of many species of Pogonophryne are virtually unknown (Eakin 1990). The few data available from the literature come primarily from the Weddell Sea, where a total of 12 species have been collected during several past cruises of the Research Vessel (RV) Polarstern carried out in the summer from 1983 to 2000 (Ekau 1988, Schwarzbach 1988, Arntz \& Gutt 1999, Arntz \& Brey 2001). Based on stomach contents analysis, Pogonophryne includes primarily benthic or suprabenthic feeders, which rely on small prey found on the sea floor or above it (Olaso et al. 2000). From an ecomorphological point of view, Pogonophryne species have smaller eyes, medium or larger mental barbels and a more specialized diet than other artedidraconids (Lombarte et al. 2003). Among the most abundant species, P. marmorata was found to feed on amphipods, isopods, mysids and occasionally on polychaetes, whereas $P$. barsukovi and $P$. permitini preferentially fed on amphipods, isopods and molluscs (Schwarzbach 1988, Olaso et al. 2000, Lombarte et al. 2003). Pogonophryne scotti relied on larger prey, such as fishes, decapods, euphausiids and cumaceans, having the largest mouth among the four species studied (Lombarte et al. 2003).

Macroscopic analyses of gonads gathered some preliminary information on the reproductive biology of $P$. barsukovi, $P$. mentella and $P$. scotti, although this was based only on one or two specimens each (Duhamel et al. 1993). Absolute fecundity was positively related to fish size and ranged from $\sim 1200$ eggs/female for $P$. barsukovi (20-24 cm total length (TL)) to $\sim 10000$ eggs/female for $P$. scotti $(28 \mathrm{~cm}$ TL). Egg size in mature females was similar among the three species
$(2.2-2.6 \mathrm{~mm})$. According to the stage of gonad development at sampling time, $P$. barsukovi and $P$. mentella were considered late autumn spawners, whereas $P$. scotti probably spawned in winter (Duhamel et al. 1993).

The aim of this study is to fill in the gap of knowledge on some life history traits of Pogonophryne species. Starting from an abundant sampling for the genera obtained during two recent cruises of the RV Polarstern in the southern Weddell Sea (PS82 and PS96, Table I), we analysed 18 specimens of plunderfishes belonging to three different species (Pogonophryne barsukovi Andriashev, 1967; Pogonophryne immaculata Eakin, 1981; Pogonophryne scotti Regan, 1914). Our results provide further insight into their reproductive traits based on both macroscopic and histological analyses of gonads, as well as the first data on individual ages estimated by means of otolith readings.

\section{Materials and methods}

\section{Fish sampling}

Fish samples were collected during two bottom trawl (BT) surveys carried out aboard the RV Polarstern in the south-eastern Weddell Sea (cruise ANT-XXIX/9, PS82, 19 December 2013-5 March 2014, and cruise ANT-XXXI/2, PS96, 6 December 2015-14 February 2016) (Table I) (Knust \& Schröder 2014, Schröder 2016). Sampling was conducted using two different gears: an otter BT with a mouth opening of 2.5-3.2 $\mathrm{m} \times 16-18 \mathrm{~m}$ and a mesh size of $40 \mathrm{~mm}$ in the cod end towed at 3 knots for $30 \mathrm{~min}$, and an Agassiz trawl (AGT) with a rigid frame of $3.5 \mathrm{~m}$ and a mesh size of $10 \mathrm{~mm}$ in the cod end towed at $1 \mathrm{knot}$ for $10 \mathrm{~min}$. The surveyed 


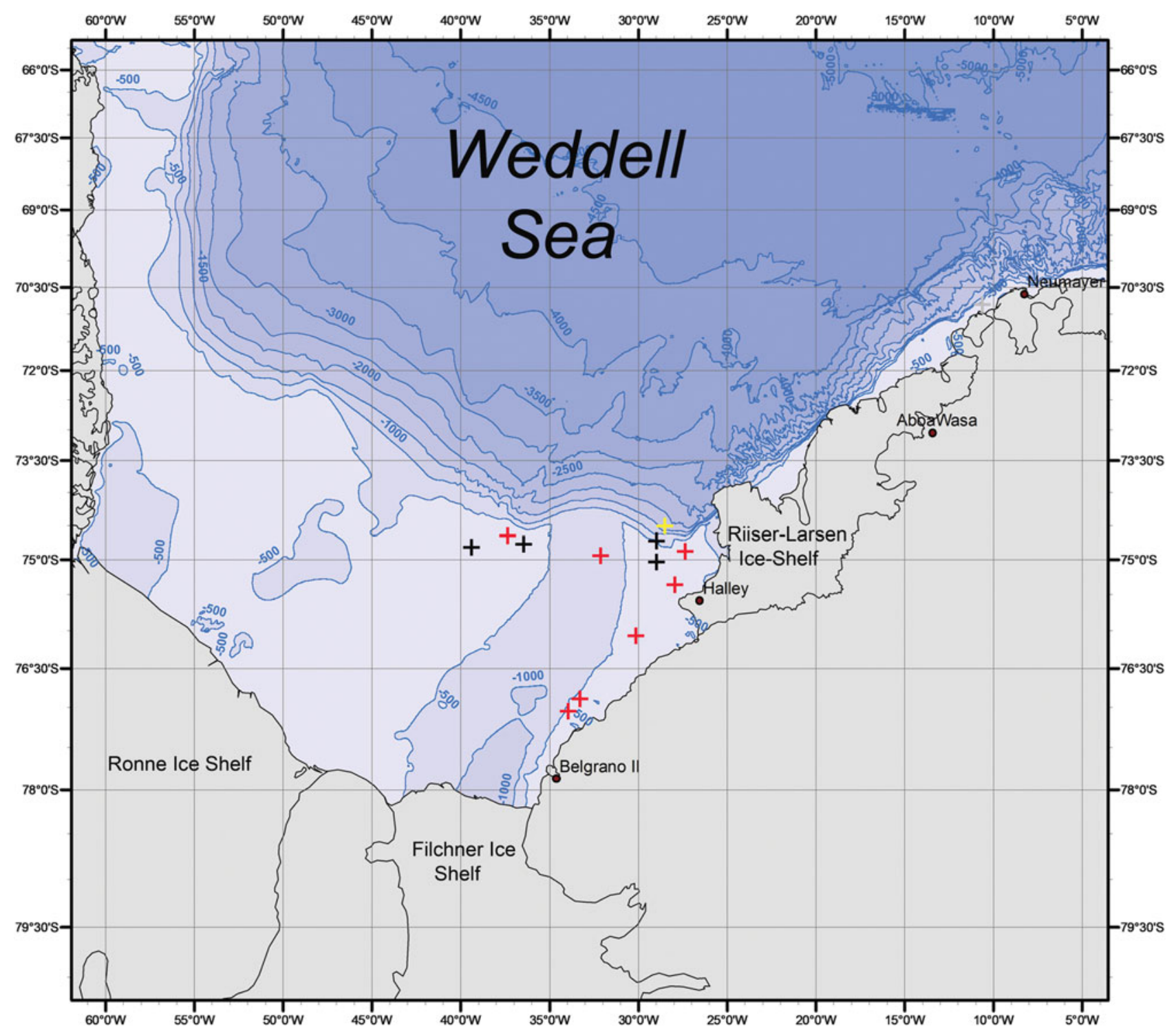

Fig. 1. Map of the study area, showing the geographical positions of sampling stations in the south-eastern Weddell Sea for Pogonophryne barsukovi (black crosses), Pogonophryne immaculata (yellow crosses) and Pogonophryne scotti (red crosses).

area encompassed the continental shelf located in the eastern and western sides of the Filchner Trough, with one sample collected at the mouth of the trough (Fig. 1).

At the end of each tow, fish samples were sorted to species and individually measured as total length $(\mathrm{TL}, \mathrm{cm})$ and weighed as total mass (TM, g). Sex and gonad stage of development were macroscopically assessed according to a five-point scale (Kock \& Kellermann 1991). The species identification within the genus Pogonophryne was carried out according to body morphology (Balushkin \& Eakin 1998, Eakin et al. 2008, 2009) and genetic analyses. Each fish was dissected and the gonads weighed as total mass (GM, g) and stored in Dietrich solution for further analysis.
Sagittal otoliths were removed from the otic capsule, cleaned of adhering tissue and stored dry. A small portion of fin or muscle was preserved in $95 \%$ ethanol at $4^{\circ} \mathrm{C}$ for genetic analyses.

\section{Laboratory activities}

For histological analysis, gonad subsamples were dehydrated and embedded in paraplast. Following a standard protocol, serial transverse sections of 5-7 $\mu \mathrm{m}$ were obtained using a rotary microtome and put on slides, dried at room temperature and stained with haematoxylin and eosin (Pearse 1985). Gonad sections were then viewed at $10-100 \times$ magnification under a light microscope (Leica DM400B) linked to a digitized 


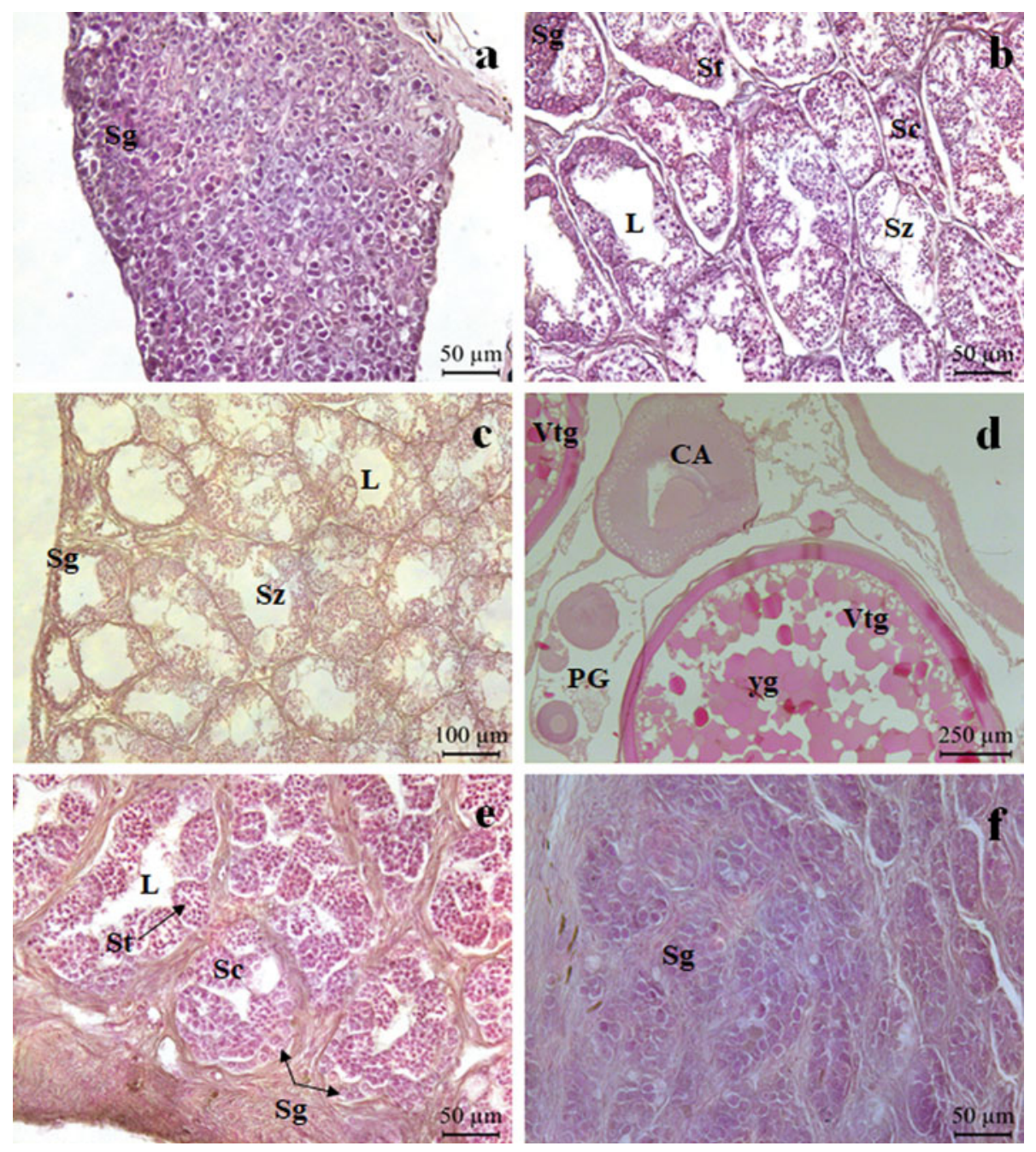

Fig. 2. Micrographs of gonad histological sections of Pogonophryne spp. at various stages of development. Pogonophryne barsukovi: a. immature male, b. developing male, c. regressing male, d. spawning-capable female. Pogonophryne immaculata: e. developing male. Pogonophryne scotti: f. immature male, g. developing male, h. immature female, i. developing female, l. regressing female. $\mathrm{A}=$ atretic oocytes, $\mathrm{CA}=$ cortical alveoli, $\mathrm{L}=$ lumen, $\mathrm{Oo}=$ oogonia, $\mathrm{PG}=$ primary growth oocytes, $\mathrm{POF}=$ postovulatory follicles, $\mathrm{Sc}=$ spermatocytes, $\mathrm{Sg}=$ spermatogonia, $\mathrm{St}=$ spermatids, $\mathrm{Sz}=$ spermatozoa, $\mathrm{Vtg}=$ vitellogenic, $\mathrm{Yg}=$ yolk granules .

computer video system (Leica Application Suite 4.3.0) through a charge-coupled device camera (Leica DFC 420). Histological stage of gonad maturity was assigned for both sexes according to a five-phase scale (BrownPeterson et al. 2011). In spawning females, a subsample of gonads was weighed and washed out in a Petri dish to manually separate oocytes of various sizes. All oocytes were then counted and measured as maximum diameter using a stereomicroscope. In order to estimate total fecundity $\left(F_{\text {tot }}\right.$, eggs/female $)$, the number of late vitellogenic oocytes in the whole gonads was inferred from the weighed subsample applying the gravimetric method (Murua et al. 2003). The relative fecundity $\left(F_{\text {rel }}\right.$, eggs $\left.g^{-1}\right)$ was derived from the $F_{\text {tot }}$ and $T M$ of fish. The extent of reproductive investment or gonadal development was assessed in both sexes by calculating the gonadosomatic index (GSI), expressed as gonad mass as a percentage of total body mass.

Sagittal otoliths were measured along the two major axes (length, OL; width, OW) with an accuracy of $0.01 \mathrm{~mm}$ and weighed (OM, mg). For ageing purposes, one otolith for each individual was randomly selected and burned in an oven at $350^{\circ} \mathrm{C}$ to enhance the contrast of the inner structure. Otoliths were then embedded in epoxy resin (Crystalbond 509 Amber) to obtain transverse sections through a grinding and polishing process. Otolith sections were viewed under reflected light using a stereomicroscope at 25-40x magnifications. According to the growth pattern commonly described in notothenioids (e.g. North 1988, 

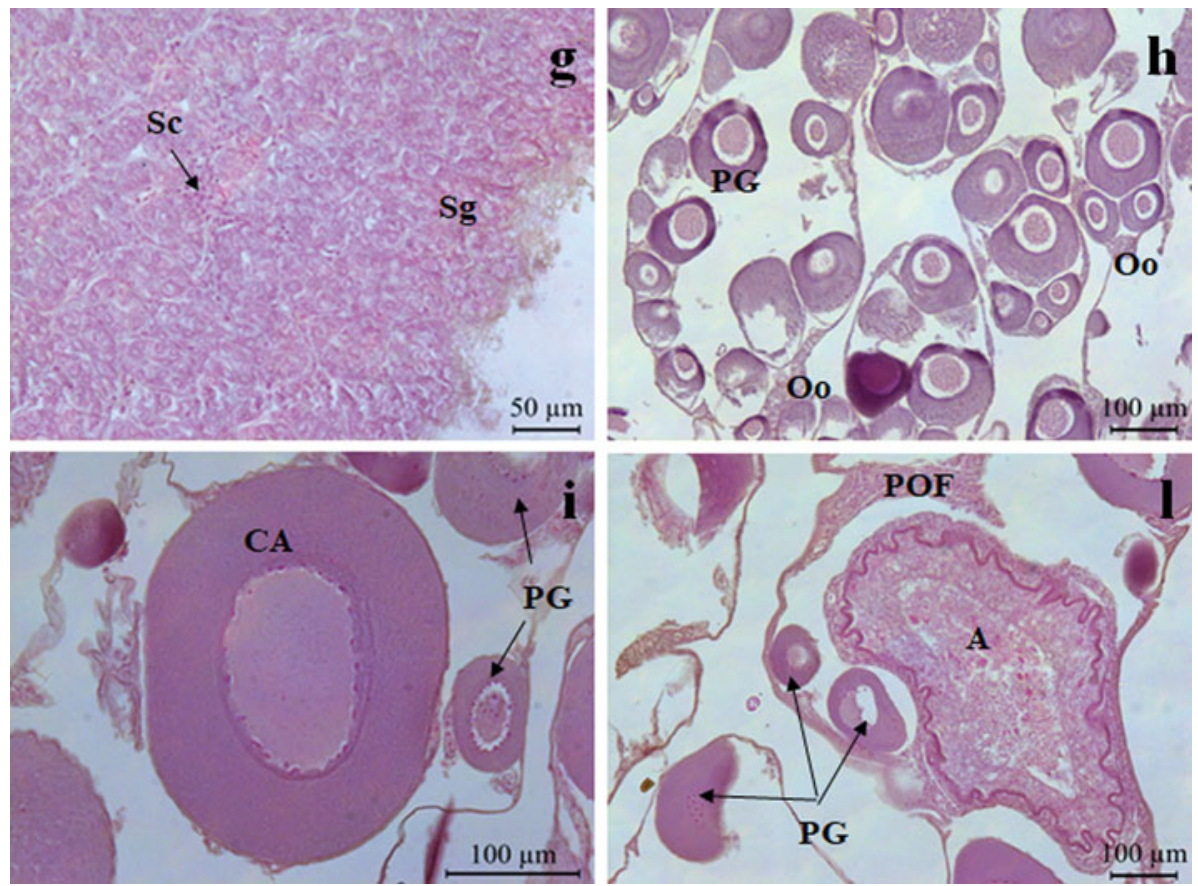

Fig. 2. Continued.

White 1991), individual age was estimated by counting the translucent/opaque zones from the primordium to the otolith margin, assuming that they were laid down annually. Two blind readings were carried out by a single reader and the mean value taken as individual age.

\section{Results}

Pogonophryne barsukovi

Four males ranging between 12 and $20 \mathrm{~cm}$ TL and 21 and $109 \mathrm{~g}$ and a single female of $22 \mathrm{~cm} \mathrm{TL}$ and $139 \mathrm{~g}$ were collected by BT at four stations located between 416 and

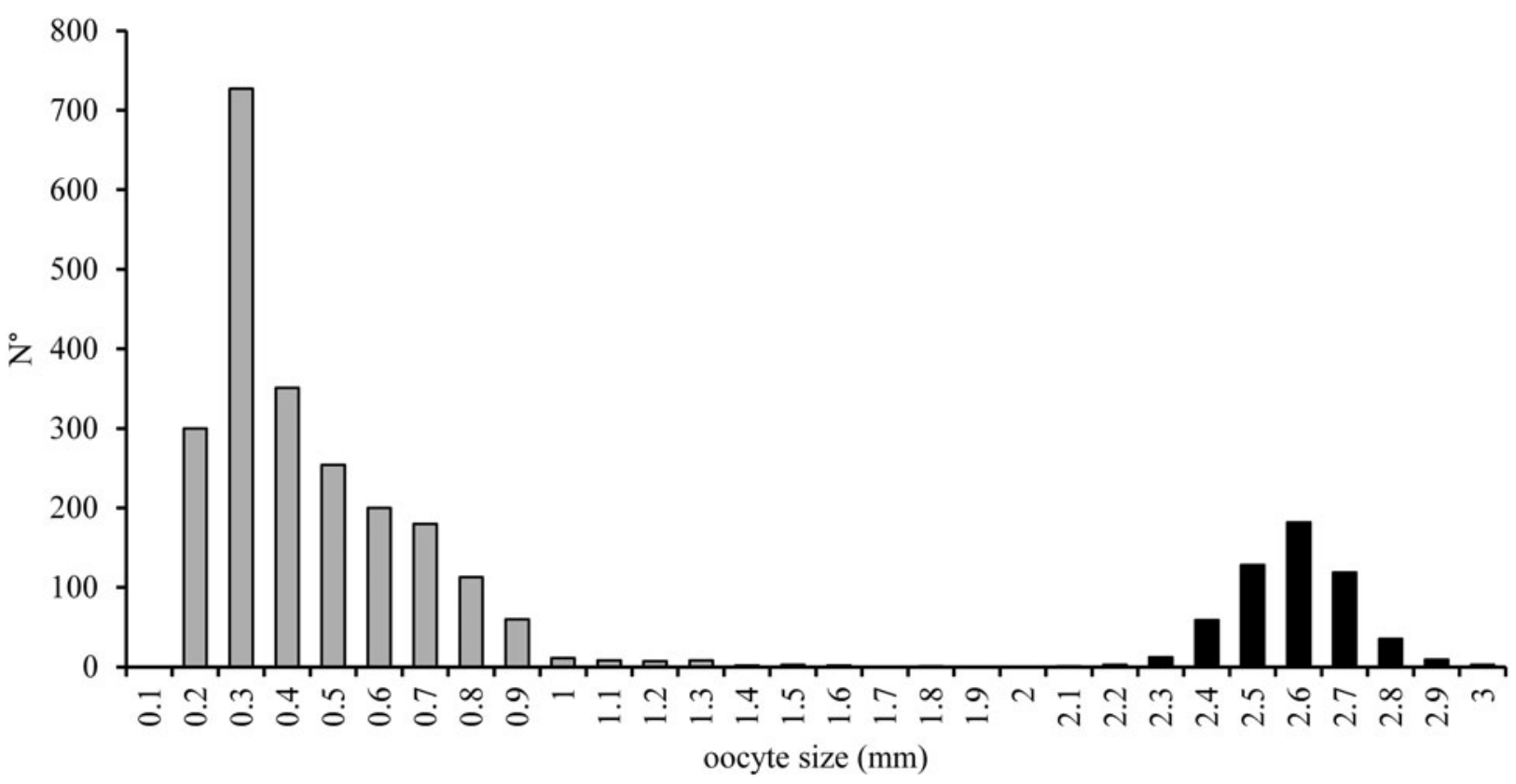

Fig. 3. Size frequency of pre-vitellogenic (grey bars) and vitellogenic oocytes (black bars) in the ovary of a spawning female of Pogonophryne barsukovi. 


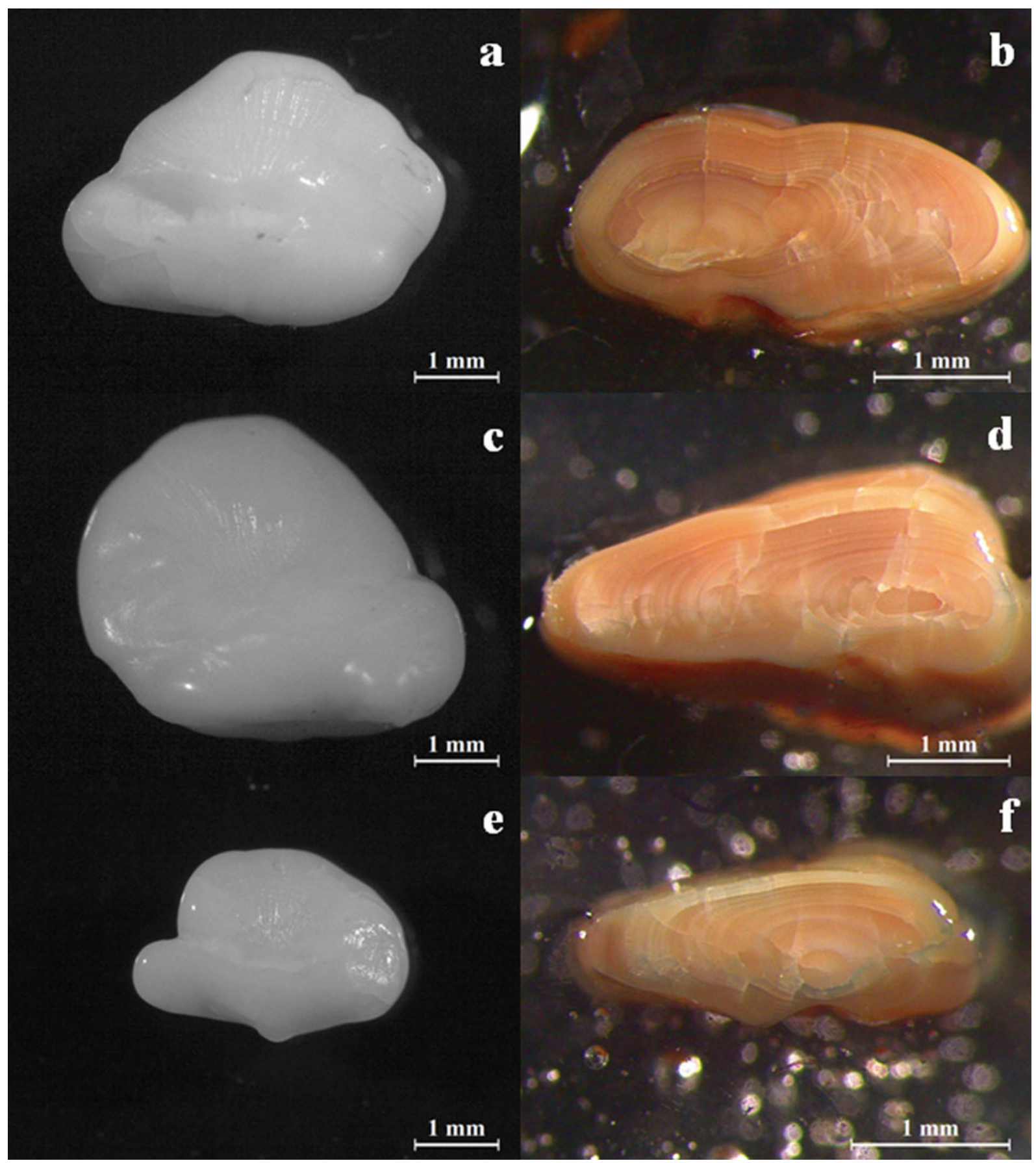

Fig. 4. Micrographs of whole otoliths (proximal side up, on the left) and sectioned otoliths (on the right) of Pogonophryne spp. a. \& b. Pogonophryne barsukovi (male, 18 years old). c. \& d. Pogonophryne immaculata (male, 16 years old).

e. \& f. Pogonophryne scotti (female, 10 years old).

$769 \mathrm{~m}$ depth (Fig. 1). The smaller male (12 cm TL) was immature (GSI 0.01\%), with thread-like testes consisting exclusively of spermatogonia (Fig. 2a). Two males (GSI 3.7-4.4\%) were in the developing phase, with lobules containing all stages of spermatogenesis, such as spermatogonia, spermatocytes, spermatids and spermatozoa (Fig. 2b). The other male (GSI 3.2\%) was regressing, with large and empty lumina and lobules with a few residual spermatozoa and scattered spermatogonia at the periphery (Fig. 2c). The single female (GSI 7.9\%) was in early spawning condition, with large ovaries composed of primary growth (pre-vitellogenic), cortical alveoli and vitellogenic oocytes with coalescent yolk granules (Fig. 2d). Gonad 
maturation in this female followed a group-synchronous development, showing two well-separated groups of pre-vitellogenic and vitellogenic oocytes of $0.1-1.6 \mathrm{~mm}$ and $2.3-3.0 \mathrm{~mm}$, respectively (Fig. 3). $F_{\text {tot }}$ and $F_{\text {rel }}$ were

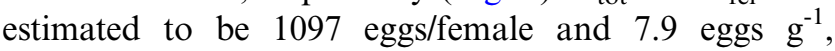
respectively.

Sagittal otoliths had an ovate shape (Fig. 4a), measuring 4.4-5.4 mm (OL) and 3.2-3.5 mm (OW) and weighing $27.6-32.5 \mathrm{mg}$. Based on transverse sections obtained only from the three largest males (19-20 cm TL), age estimates ranged between 16 and 18 years (Fig. 4b).

\section{Pogonophryne immaculata}

Three adult males ranging between 26 and $28 \mathrm{~cm}$ TL and 199 and $279 \mathrm{~g}$ were caught by the AGT net deployed at $1750 \mathrm{~m}$ on the steep slope north of Halley Bay (Fig. 1). All specimens were in the developing phase (GSI $0.5-0.8 \%$ ), being characterized by large testes with lobules containing cysts of spermatogonia, spermatocytes and spermatids, as well as evident lumina free of spermatozoa (Fig. 2e).

Sagittal otoliths had an ovate shape (Fig. 4c), with a size range of $4.1-5.4 \mathrm{~mm}(\mathrm{OL})$ and $3.9-4.2 \mathrm{~mm}(\mathrm{OW})$ and a TM of $31.3-48.2 \mathrm{mg}$. As in the previous species, individual age estimates for all specimens caught ranged between 16 and 18 years (Fig. 4d).

\section{Pogonophryne scotti}

Pogonophryne scotti was the most common and abundant species within the genus in both cruises. The species was collected in three AGT and five BT stations at 473-623 m and $265-377 \mathrm{~m}$ depths, respectively, mainly located on the shelf east of the Filchner Trough (Fig. 1). Fish size ranged between 8.5 and $22 \mathrm{~cm} \mathrm{TL}$ and 6 and $187 \mathrm{~g}$ for males $(n=5)$ and between 11.0 and $28.5 \mathrm{~cm}$ TL and 10 and $367 \mathrm{~g}$ for females $(n=5)$. Four males were immature (GSI $0.01-0.02 \%$ ), with very small gonads characterized by lobules filled solely by spermatogonia and with no visible lumina (Fig. 2f). The largest male $(22 \mathrm{~cm} \mathrm{TL})$ was in the early developing sub-phase (GSI $0.04 \%$ ), with testes of increased size and spermatocysts dominated by spermatogonia and spermatocytes (Fig. 2g). The smallest female (11 cm TL) was immature (GSI $0.4 \%$ ), with ovaries filled by oogonia and primary growth oocytes (Fig. 2h). A single female was in the early developing sub-phase (GSI 1.5\%), with the germinal epithelium consisting of primary growth and cortical alveoli oocytes (Fig. 2i). The remaining females were all regressing (GSI 0.4-1.2\%), with flaccid ovaries containing postovulatory follicles and atretic oocytes, as well as a few primary growth and cortical alveoli oocytes (Fig. 21).
Sagittal otoliths had a triangular shape (Fig. 4e), with a size range of 3.2-6.6 mm (OL) and 2.3-4.7 $\mathrm{mm}(\mathrm{OW})$ and a TM of $9.0-63.7 \mathrm{mg}$. Based on individual otolith readings, performed on all specimens except for the smallest male, age estimates were 10-16 and 10-22 years in males and females, respectively (Fig. 4f).

\section{Discussion}

\section{Spatial distribution}

The two recent cruises in the southern Weddell Sea (PS82 and PS96) confirmed the presence of P. barsukovi and $P$. scotti in this area, strengthening the hypothesis they had a circum-Antarctic distribution (Eakin 1990). Their depth distributions were quite similar to each other and fell within the range reported elsewhere (Eastman 2017). The three specimens of $P$. immaculata analysed in this study represent the first occurrences of this species in the Weddell Sea. Indeed, this rare species was only known from the holotype collected at the South Orkney Islands (Eakin 1990) and seven other specimens caught on the continental slope of the Ross Sea (Eakin et al. 2009). With a depth range of $\sim 1200-2500 \mathrm{~m}$ (Eastman 2017), $P$. immaculata is by far the deepest-living species of Pogonophryne and the second deepest-living species among notothenioids (Eakin et al. 2009).

\section{Reproductive traits}

Except for a juvenile, all of the other specimens of $P$. barsukovi were adults close to the maximum size reported so far for the species $(25 \mathrm{~cm} \mathrm{TL})$ (Eastman 2019). The evidence of males in the developing phase of gonad maturity and a single female in early spawning condition indicates that this species probably spawns in early autumn in the Weddell Sea. The reproductive effort of females in terms of GSI, $F_{\text {tot }}$ and $F_{\text {rel }}$ falls within the ranges previously reported (Duhamel et al. 1993), closely resembling another species of comparable maximum size (Pogonophryne ventrimaculata, $26 \mathrm{~cm} \mathrm{TL}$ ) reported in the same area (Ekau 1991).

Males of P. immaculata collected in the Weddell Sea were larger than reported in literature for samples collected in the Ross Sea $(22-25 \mathrm{~cm}$ TL) (Eakin et al. 2009). This observation enables us to update the maximum size of the species from 25 to $28 \mathrm{~cm} \mathrm{TL}$. Based on the developmental stage of their gonads, P. immaculata should probably spawn in autumn.

Pogonophryne scotti was the most common species within the genus, consistent with the results obtained during a recent seabed imaging survey conducted in the Weddell Sea (La Mesa et al. 2019). Notably, the lack of large adult males in the samples could be related to their spatial segregation during parental egg guarding, 
as described in the northern Weddell Sea in the same period (February-March) (Jones \& Near 2012). The presence of regressing or post-spawning females with ovaries containing postovulatory follicles indicates a recent spawning, possibly occurring in spring or early summer. Compared to the other two species, P. scotti showed greater fecundity, consistent with their maximum size reported in the literature ( $32 \mathrm{~cm}$ TL) (Eastman 2019).

Interestingly, nesting males of $P$. scotti exhibited an evident sexual dimorphism in the size and colour of the anterior lobe of the second dorsal fin (Jones \& Near 2012), a characteristic shared with $P$. barsukovi (Eakin 1990, present data) and P. immaculata (Eakin et al. 2009). As sexual dichromatism is generally correlated with male parental care and nesting behaviour (Mank et al. 2005) and considering their similar low fecundities, we hypothesize that $P$. barsukovi and $P$. immaculata also evolved similar reproductive strategies, including parental care and nest guarding.

\section{Age and growth}

As has been reported for many other notothenioids (reviewed in North 1988, White 1991, Kock \& Everson 1998), the use of otolith sectioning appears to provide a method for estimating the age of barbeled plunderfishes. Although based on presumed annual deposition of neighbouring opaque and translucent zones, this study is the first attempt to age specimens of Pogonophryne spp. Pogonophryne barsukovi and P. immaculata attained the same maximum age. These estimates were significantly higher than those reported for other (smaller) artedidraconids, such as Artedidraco skottsbergi and Dolloidraco longedorsalis (Meneghesso et al. 2017). Pogonophryne scotti was characterized by an evident sexual dimorphism in body size and longevity, with females being larger and older than males. In general, all species of Pogonophryne investigated in this study share common traits, such as small maximum size and longevity of nearly 20 years, which suggest a relatively low body growth rate, consistent with their low scope for activity and sluggish mode of life (Zimmermann \& Hubold 1998).

\section{Acknowledgements}

We sincerely thank the captain and all the crew members and personnel working aboard the RV Polarstern during the cruises ANT-XXIX/9 (PS82) and ANT-XXXI/2 (PS96) for their support during field sampling activities. The authors are also grateful to Nils Koschnick, Magnus Lucassen, Maj Wetjen, Kai Wätjen and Rainer Knust (Alfred Wegener Institute Helmholtz Centre for Polar and Marine Research) for their support in sample collection. We wish to thank two anonymous reviewers, whose comments greatly improved the early draft of the manuscript.

\section{Author contributions}

MLM conceived and wrote the paper, FD performed the histological analysis of gonads, ER and CP conducted the field sampling and TJN and EP performed the genetic analyses. Each author contributed significantly to data analyses and manuscript editing before submission.

\section{Financial support}

CP acknowledges financial support from the University of Padua (BIRD164793/16, SEED2019) and from the European Marie Curie project 'Polarexpress' Grant No. 622320. This study was conducted within the project 2013/ C1.07, and MLM acknowledges financial support of the Italian National Antarctic Research Program (PNRA).

\section{References}

Arntz, W.E. \& Brey, T. 2001. The expedition ANTARKTIS XVII/3 (EASIZ III) of RV 'Polarstern' in 2000. Berichte zur PolarforschungReports on Polar Research, 402, 1-181.

Arntz, W.E. \& GutT, J. 1999. The Expedition ANTARKTIS XV/3 (EASIZ II) of RV 'Polarstern' in 1998. Berichte zur Polarforschung Reports on Polar Research, 301, 1-244.

Balushkin, A.V. \& Eakin, R.R. 1998. A new toad plunderfish Pogonophryne fusca sp. nova (Fam. Artedidraconidae: Notothenioidei) with notes on species composition and species groups in the genus Pogonophryne Regan. Journal of Ichthyology, 38, 574-579.

Balushinin, A.V. \& Korolkova, E.D. 2013. New species of plunderfish Pogonophryne favosa sp. n. (Artedidraconidae, Notothenioidei, Perciformes) from the Cosmonauts Sea (Antarctica) with the description in artedidraconids of unusual anatomical structuresconvexitas superaxillaris. Journal of Ichthyology, 53, 10.1134/ S0032945213050020.

Balushrin, A.V. \& Spodareva, V.V. 2013. Dwarf toad plunderfish Pogonophryne minor sp. n. (Artedidraconidae; Notothenioidei; Perciformes) - a new species and one of the smallest species of autochthonous ichthyofauna of marginal seas of the Antarctic continent. Journal of Ichthyology, 53, 10.1134/S0032945213010025.

Balushinin, A.V., Petrov, A.F. \& Prutko, V.G. 2010. Pogonophryne brevibarbata sp. nov. (Artedidraconidae, Notothenioidei, Perciformes) a new species of toadlike plunderfish from the Ross Sea, Antarctica. Proceedings of the Zoological Institute of the Russian Academy of Sciences USSR, 314, 381-386.

Brown-Peterson, N.J., Wyanski, D.M., Saborido-Rey, F., Macewicz, B.J. \& LowerRe-BARbieri, S.K. 2011. A standardized terminology for describing reproductive development in fishes. Marine and Coastal Fisheries: Dynamics, Management, and Ecosystem Science, 3, 10.1080/19425120.2011.555724.

Duhamel, G., Kock, K.H., Balguerias, E. \& Hureau, J.C. 1993. Reproduction in fish of the Weddell Sea. Polar Biology, 13, 10.1007/ BF00238929.

EAKIN, R.R. 1977. Morphology and distribution of species in the genus Pogonophryne (Pisces, Harpagiferidae). Antarctic Research Series, 28, $1-20$.

Eakin, R.R. 1990. Artedidraconidae. In Gon, O. \& Heemstra, P.C., eds. Fishes of the Southern Ocean. Grahamstown: J.L.B. Smith Institute of Ichthyology, 332-356.

Eakin, R.R., Eastman, J.T. \& Matallanas, J. 2008. New species of Pogonophryne (Pisces, Artedidraconidae) from the Bellingshausen Sea, Antarctica. Polar Biology, 31, 10.1007/s00300008-0455-7. 
Eakin, R.R., Eastman, J.T. \& Near, T.J. 2009. A new species and a molecular phylogenetic analysis of the Antarctic fish genus Pogonophryne (Notothenioidei: Artedidraconidae). Copeia, 4, 10.1643/CI-09-024.

Eastman, J.T. 2017. Bathymetric distributions of notothenioid fishes. Polar Biology, 40, 10.1007/s00300-017-2128-x.

EASTMAN, J.T. 2019. An analysis of maximum body size and designation of size categories for notothenioid fishes. Polar Biology, 42, 10.1007/ s00300-019-02502-7.

EKAU, W. 1988. Ecomorphology of nototheniid fish from the Weddell Sea, Antarctica. Berichte zur Polarforschung - Reports on Polar Research, 51, 1-140.

EkAU, W. 1991. Reproduction in high Antarctic fishes. Meeresforschung, 33, 159-167.

Jones, C.D. \& Near, T.J. 2012. The reproductive behaviour of Pogonophryne scotti confirms widespread egg-guarding parental care among Antarctic notothenioids. Journal of Fish Biology, 80, 10.1111/ j.1095-8649.2012.03282.x.

KNust, R. \& SCHRÖDER, M. 2014. The expedition PS82 of the research vessel Polarstern to the southern Weddell Sea in 2013/2014. Berichte zur Polarforschung - Reports on Polar Research, 680, 1-155.

Kock, K.-H. \& Everson, I. 1998. Age, growth and maximum size of Antarctic notothenioid fish revisited. In Di Prisco, G., PIsAno, E. \& Clarke A., eds. Fishes of Antarctica: a biological overview. Milan: Springer, 29-40.

Kock, K.-H. \& Kellermann, A. 1991. Reproduction in Antarctic notothenioid fish: a review. Antarctic Science, 3, 10.1017/ S0954102091000172.

La Mesa, M., Piepenburg, D., Pineda-Metz, S., Riginella, E. \& EASTMAN J.T. 2019. Spatial distribution and habitat preferences of demersal fish assemblages in the southeastern Weddell Sea (Southern Ocean). Polar Biology, 42, 10.1007/s00300-019-02495-3.

Lombarte, A., Olaso, I. \& Bozzano, A. 2003. Ecomorphological trends in the Artedidraconidae (Pisces: Perciformes: Notothenioidei) of the Weddell Sea. Antarctic Science, 15, 10.1017/S0954102003001196.

Mank, J.E., Promislow, D.E.L. \& Avise, J.C. 2005. Phylogenetic perspectives in the evolution of parental care in ray-finned fishes. Evolution, 59, 10.1111/j.0014-3820.2005.tb01806.x.

Meneghesso, C., Riginella, E., La Mesa, M., Donato, F. \& Mazzoldi, C. 2017. Age and reproduction in two Antarctic plunderfishes (Artedidraconidae) from the Weddell Sea. Polar Biology, 40, 10.1007/s00300-016-1919-9.
Murua, H., Kraus, G., Saborido-Rey, F., Witthames, P.R., Thorsen, A. \& JUNQUERA, S. 2003. Procedures to estimate fecundity of marine fish species in relation to their reproductive strategy. Journal of Northwest Atlantic Fishery Science, 33, 33-54.

North, A. 1988. Age of Antarctic fish: validation of the timing of annuli formation in otoliths and scales. Cybium, 12, 107-114.

Olaso, I., Rauschert, M. \& DE Broyer, C. 2000. Trophic ecology of the family Artedidraconidae (Pisces: Osteichthyes) and its impact on the eastern Weddell Sea benthic system. Marine Ecology Progress Series, 194, 10.3354/meps 194143.

Pearse, A.G.E. 1985. Histochemistry. Theoretical and applied analytical technology. Edinburgh: Churchill Livingstone, $624 \mathrm{pp}$.

SCHRÖDER, M. 2016. The expedition PS96 of the research vessel Polarstern to the southern Weddell Sea in 2015/2016. Berichte zur Polarforschung - Reports on Polar Research, 700, 1-142.

Schwarzbach, W. 1988. The demersal fish fauna of the eastern and southern Weddell Sea: geographical distribution, feeding of fishes and their trophic position in the food web. Berichte zur Polarforschung - Reports on Polar Research, 54, 1-94.

Shandikov, A.G. \& Eakin, R.R. 2013. Pogonophryne neyelovi, a new species of Antarctic shortbarbeled plunderfish (Perciformes, Notothenioidei, Artedidraconidae) from the deep Ross Sea. Zookeys, 296, $10.3897 /$ zookeys.296.4295.

Shandikov, A.G., Eakin, R.R. \& Usachev, S. 2013. Pogonophryne tronio, a new species of Antarctic short-barbeled plunderfish (Perciformes: Notothenioidei: Artedidraconidae) from the deep Ross Sea with new data on Pogonophryne brevibarbata Spodareva \& Balushkin 2014. Polar Biology, 36, 10.1007/s00300-012-1258-4.

Spodareva, V.V. \& Balushkin A.V. 2014. Description of a new species of plunderfish of genus Pogonophryne (Perciformes: Artedidraconidae) from the Bransfield Strait (Antarctica) with a key for the identification of species of the group 'marmorata'. Journal of Ichthyology, 54, 10.1134/S0032945214010135.

White, M.G. 1991. Age determination in Antarctic fish. In Di Prisco, G., Maresca, B. \& Tota, B., eds. Biology of Antarctic fish. Berlin: Springer, $87-100$.

Zimmermann, C. \& Hubold, G. 1998. Respiration and activity of Arctic and Antarctic fish with different modes of life: a multivariate analysis of experimental data. In Di Prisco, G., Pisano, E. \& Clarke A., eds. Fishes of Antarctica: a biological overview. Milan: Springer, 163-174. 